\title{
The microbial burden in chronic suppurative otitis media patients along with their antibiogram
}

\author{
R Sharma S. ${ }^{1}$, Singh S. ${ }^{2 *}$, Mishra A. ${ }^{3}$, Singh P. ${ }^{4}$ \\ DOI: https://doi.org/10.17511/jopm.2020.i03.02 \\ 1 Shweta R Sharma, Assistant Professor, Department of Pathology, Teerthanker Mahavir Medical College and Research Centre, Moradabad, \\ Uttar Pradesh, India. \\ 2* Sudhir Singh, Associate Professor, Department of Microbiology, Teerthanker Mahavir Medical College and Research Centre, Moradabad, \\ Uttar Pradesh, India. \\ 3 Amit Mishra, Assistant Professor, Department of Medicine, Teerthanker Mahavir Medical College and Research Centre, Moradabad, Uttar \\ Pradesh, India. \\ 4 Prachi Singh, Post Graduate Student, Department of Pathology, Teerthanker Mahavir Medical College and Research Centre, Moradabad, \\ Uttar Pradesh, India.
}

Introduction: Chronic suppurative otitis media (CSOM) is a common health problem in countries with low socio-economic strata because of poor nutrition, population burden, low hygienic condition, insufficient health care, and repeated upper respiratory tract infection (URTI). Untreated cases of CSOM result in complications ranging from persistent otorrhoea, mastoiditis, labyrinthitis, facial nerve palsy to intracranial abscesses or thromboses. Microbiological profile and their antibiotic sensitivity pattern are essential to enable proper treatment of this disease and preventing the development of complications. Material and Methods: The current study was designed to identify the pathogenic agents causing CSOM and to understand their antimicrobial resistance pattern who attended ENT Department of this hospital between July 2017 to June 2019. Results: Among 496 clinical samples, microbes were seen in $329(66.3 \%)$ cases with predominant male $(66.3 \%)$ distribution and age group of $11-20$ years (31\%). Pseudomonas spp. (50.7\%) is predominantly isolated. It showed resistance to aminoglycosides and fluoroquinolones but was found sensitive to carbapenems with a resistance rate of 1.2\%. ESBL (Extended-spectrum $\beta$ - lactamase) detection was seen in $30.9 \%$ of GNB while MBL (Metallo $\beta$ - lactamase) was detected in $2.7 \%$ of cases. Conclusions: There should be a minimum gap between the onset of symptoms and the treatment provided to prevent complications of CSOM and also the complicated cases should be referred to specialized centers for better management.

Keywords: CSOM, Antimicrobial resistance, Bacterial profile

\section{Corresponding Author}

Sudhir Singh, Associate Professor, Department of Microbiology, Teerthanker Mahavir Medical College and Research Centre, Moradabad, Uttar Pradesh, India.

Email: tmumicrobiology.microbiology@gmail.com
How to Cite this Article

Sharma SR, Singh S, Mishra A, Singh P. The microbial burden in chronic suppurative otitis media patients along with their antibiogram. Trop J Pathol Microbiol. 2020;6(3):217-222.

Available From

https://pathology.medresearch.in/index.php/jopm/ar ticle/view/393
To Browse

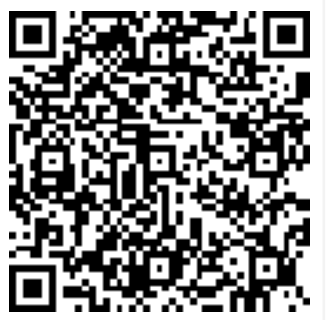

Manuscript Received 25-02-2020

Conflict of Interest No

Review Round 1
04-03-2020
Funding
Nil

Review Round 2
08-03-2020
Ethical Approval
Yes

Review Round 3

Plagiarism X-checker $17 \%$
Accepted 12-03-2020

(c) 2020 by Shweta R Sharma, Sudhir Singh, Amit Mishra, Prachi Singh and Published by Siddharth Health Research and Social Welfare Society. This is an Open Access article licensed under a Creative Commons Attribution 4.0 International License https://creativecommons.org/licenses/by/4.0/ unported [CC BY 4.0]. 


\section{Introduction}

CSOM refers to chronic inflammation of the middle ear and mastoid cavity presenting with ear discharge of three months or more along with tympanic membrane perforation [1]. It is a major public health concern and seen more commonly in developing countries with low socioeconomic status. It could be due to the result of inadequately treated acute otitis media or infection of acute suppurative otitis media (ASOM) with organisms from the external auditory canal. The common factors related to CSOM are malnutrition, overcrowding, poor hygienic condition, insufficient health care, and repeated upper respiratory tract infection [2]. Otitis media is common in children, as their Eustachian tube is shorter and more horizontal than adults [3]. CSOM has multifactorial pathogenesis and factors affecting this problem are genetic predispositions, infections, allergies, environmental, social and racial factors and Eustachian tube dysfunction [4].

Repeated inflammation due to attacks of suppurative otitis media leads to mucosal ulceration followed by healing with granulation tissue formation and destroying the surrounding bony structures and leads to various complications ranging from persistent otorrhoea, mastoiditis, labyrinthitis, facial nerve palsy to more serious intracranial abscesses or thromboses [5]. Other factors that increase the risk of development of CSOM include craniofacial anomalies like cleft palate, cleft lip, microcephaly.

These anomalies are responsible for the alteration of Eustachian tube anatomy and function thereby blocking the clearance of tube and providing an enriched environment for the growth and multiplication of various micro-organisms. Organisms most commonly isolated from CSOM cases include aerobic organisms like Pseudomonas spp., Staphylococcus aureus, Proteus spp., Klebsiella pneumonia, etc. While in $5-10 \%$ of cases the infection is polymicrobial. Anaerobes and fungi also play an important role in the etiology of CSOM accounting for $25 \%$ of cases of CSOM. However, the severity of infection increases when these organisms are isolated along with other bacterial pathogens.

Microbial profile and their antibiotic sensitivity pattern are essential to enable proper treatment of this disease, and preventing complications. With the introduction of antibiotics, there was a decline in the rate of complications, however, due to the
Inadvertent use of antibiotics and the availability of over the counter drugs, there has been an increase in the incidence of multi-resistant bacteria and disease complication in return. Hence, time to time updates on the prevalence and antibiotic sensitivity pattern of causative agents would help to manage such patients. This study was designed to identify the pathogens causing CSOM and their antimicrobial resistance pattern among clinically suspected cases.

\section{Materials and Methods}

Setting: This study was conducted in the Department of Microbiology, Teerthanker Mahavir Medical College and Research Centre, Moradabad, Western Uttar Pradesh, India.

Duration: Two years between 1st July 2017 to 30th June 2019

Type of study: Prospective, observational and descriptive

Sampling method: Ear discharge was collected with the sterile swab from patients who attended ENT OPD between July 2017 to June 2019 with clinically suspected cases of CSOM. All care was taken to avoid surface contamination and the swabs transported to the microbiology section for further processing. The pus sample was processed for microscopy and inoculated on suitable culture media with incubation at $370 \mathrm{C}$ for $24-48$ hours. The isolates were identified according to standard guidelines and Antibiotic Sensitivity Testing was done by an automated sensitivity system (Vitek 2 Compact $\circledast$ ) [6].

Sample Size: A total of 496 patients with symptoms suggestive of CSOM were included in the study.

Inclusion criteria: All clinically suspected cases of CSOM attending ENT OPD before receiving any antimicrobial therapy were included in the present study.

Exclusion criteria: Patients who already received antibiotics and the patients who denied consent were excluded from the present study. Any repeat isolate from the same patient obtained on more than one occasion was also excluded from the study.

Data collection procedure and analysis: All the relevant data such as age, gender, duration of symptoms of the patients, treatment received, past history of infection, etc. were obtained and documented. The data was also entered into the 
Microsoft Excel sheet and analyzed. The results were expressed as proportions and percentages for each organism isolated in culture.

Ethical consideration: Ethical clearance was received from the institutional Ethical committee before conducting the study.

\section{Results}

In the present study, the patient's age ranged from 1 to 75 years. In 496 samples, microbes were seen in $329(66.3 \%)$ cases [bacterial-320 and fungal- 9 cases], mixed growth (contamination) in 36 (7.2\%) cases, and no growth in 131 (26.4\%) cases. Males $(66.3 \%)$ were more commonly involved compared to females (33.7\%) and age-wise distribution shows that most of the isolates were grown in the age group of $11-20$ years (31\%) followed by $21-30$ years $(29.8 \%)$ as shown in Table 1 . Pseudomonas spp. $(50.7 \%)$ is predominantly isolated followed by S. aureus $(27.9 \%)$ as shown in Table 2 . The antibiogram of gram-negative rods (GNR) is shown in Table 3 and gram-positive cocci (GPC) in Table 4. Pseudomonas spp. showed resistance to aminoglycosides and fluoroquinolones but were found sensitive to carbapenems with a resistance rate of $1.2 \%$. Acinetobacter was the most resistant organism isolated among gram-negative bacilli (GNB). All GNR were sensitive to colistin. ESBL (Extended-spectrum $\beta$ - lactamase) detection was seen in $30.9 \%$ of GNB while MBL (Metallo $\beta$ -
Lactamase) was detected in $2.7 \%$ of cases as shown in table 3. Among gram-positive isolates, S.aureus was highly resistant to first-line antibiotics with MRSA (Methicillin-resistant S.aureus) rate of $64.1 \%$, however, all were sensitive to glycopeptides (Table 4).

\section{Table-1: Age-wise and gender-wise distribution of various organisms in CSOM patients.}

\begin{tabular}{|l|l|l|l|}
\hline \multicolumn{1}{|c|}{ Age groups } & \multicolumn{1}{|c|}{ Male } & \multicolumn{1}{c|}{ Female } & \multicolumn{1}{c|}{ Total } \\
\hline $0-10$ years & 24 & 7 & $31(9.4 \%)$ \\
\hline $11-20$ years & 74 & 28 & $102(31 \%)$ \\
\hline $21-30$ years & 63 & 35 & $98(29.8 \%)$ \\
\hline $31-40$ years & 27 & 21 & $48(14.6 \%)$ \\
\hline $41-50$ years & 19 & 8 & $27(8.2 \%)$ \\
\hline $51-60$ years & 8 & 7 & $15(4.6 \%)$ \\
\hline$>60$ years & 3 & 5 & $8(2.4 \%)$ \\
\hline Total & $218(66.3 \%)$ & $111(33.7 \%)$ & 329 \\
\hline
\end{tabular}

Table-2: Distribution of micro-organisms in CSOM patients.

\begin{tabular}{|l|l|l|}
\hline \multicolumn{1}{|c|}{ Organisms isolated } & Frequency & Percentage \\
\hline Pseudomonas spp. & 167 & $50.7 \%$ \\
\hline Staphylococcus aureus & 92 & $27.9 \%$ \\
\hline E. coli & 29 & $8.8 \%$ \\
\hline Acinetobacter spp. & 11 & $3.3 \%$ \\
\hline Proteus spp. & 10 & $3.0 \%$ \\
\hline Klebsiella spp. & 6 & $1.8 \%$ \\
\hline Coagulase negative Staphylococcus & 5 & $1.5 \%$ \\
\hline Candida spp. & 9 & $2.7 \%$ \\
\hline Total & 329 & \\
\hline
\end{tabular}

Table-3: Drug Resistance pattern of gram-negative isolates in CSOM.

\begin{tabular}{|c|c|c|c|c|c|c|}
\hline Organisms & Pseudomonas spp. $(n=167)$ & E.coli $(n=29)$ & Acinetobacter spp. $(n=11)$ & $\mid$ Proteus spp. $(n=10) \mid$ & Klebsiella spp. $(n=06)$ & Total $(n=223)$ \\
\hline$G(\%)$ & $101(60.5 \%)$ & $12(41.4 \%)$ & $11(100 \%)$ & $7(70 \%)$ & $3(50 \%)$ & $134(60.1 \%)$ \\
\hline Ak (\%) & $59(35.3 \%)$ & $9(31.0 \%)$ & $10(90.9 \%)$ & $3(30 \%)$ & $2(33.3 \%)$ & $83(37.2 \%)$ \\
\hline Cf (\%) & $91(54.5 \%)$ & $19(65.5 \%)$ & $11(100 \%)$ & $9(90 \%)$ & $5(83.3 \%)$ & $135(60.5 \%)$ \\
\hline $\mathrm{Ca} / \mathrm{Ci}(\%)$ & $48(28.7 \%)$ & $6(20.7 \%)$ & $10(90.9 \%)$ & $4(40 \%)$ & $1(16.6 \%)$ & $69(30.9 \%)$ \\
\hline Co $(\%)$ & - & $21(72.4 \%)$ & $11(100 \%)$ & - & $4(66.6 \%)$ & - \\
\hline $\mathrm{Pc}(\%)$ & $19(11.3 \%)$ & - & - & - & - & - \\
\hline PT (\%) & $7(4.2 \%)$ & $3(10.3 \%)$ & $7(63.6 \%)$ & $2(20 \%)$ & $0(0 \%)$ & $19(8.5 \%)$ \\
\hline $\operatorname{Imp} / \mathrm{Mr}(\%)$ & $2(1.2 \%)$ & $1(3.4 \%)$ & $2(18.1 \%)$ & $1(10 \%)$ & $0(0 \%)$ & $6(2.7 \%)$ \\
\hline CL (\%) & $0(0 \%)$ & $0(0 \%)$ & $0(0 \%)$ & $0(0 \%)$ & $0(0 \%)$ & $0(0 \%)$ \\
\hline ESBL (\%) & $48(28.7 \%)$ & $6(20.7 \%)$ & $10(90.9 \%)$ & $4(40 \%)$ & $1(16.6 \%)$ & $69(30.9 \%)$ \\
\hline MBL (\%) & $2(1.2 \%)$ & $1(3.4 \%)$ & $2(18.1 \%)$ & $1(10 \%)$ & $0(0 \%)$ & $6(2.7 \%)$ \\
\hline
\end{tabular}

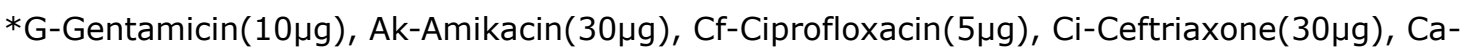

Ceftazidime $(30 \mu \mathrm{g})$, CoCotrimoxazole, Pc- Piperacillin $(100 \mu \mathrm{g})$, PT- Piperacillin- Tazobactam(100/10 $\mathrm{gg})$, ImpImipenem(10 $\mathrm{g})$, CL- Colistin $(10 \mu \mathrm{g})$, ESBL-Extended spectrum $\beta$ - lactamase, MBL- Metallo $\beta$ - lactamase. 
Table-4: Drug resistance pattern in gram positive isolates.

\begin{tabular}{|l|l|l|l|}
\hline Gram positive cocci & S. aureus (n=92) & CoNS (n=5) & Total (n=97) \\
\hline T (\%) & $84(91.3 \%)$ & $3(60 \%)$ & $87(89.7 \%)$ \\
\hline E (\%) & $82(89.1 \%)$ & $3(60 \%)$ & $85(87.7 \%)$ \\
\hline Cf (\%) & $84(91.3 \%)$ & $4(80 \%)$ & $88(90.7 \%)$ \\
\hline Co (\%) & $78(84.7 \%)$ & $3(60 \%)$ & $81(83.5 \%)$ \\
\hline Cn (\%) & $59(64.1 \%)$ & $2(40 \%)$ & $61(62.9 \%)$ \\
\hline AC (\%) & $38(41.3 \%)$ & $1(20 \%)$ & $39(40.2 \%)$ \\
\hline Va (\%) & $0(0 \%)$ & $0(0 \%)$ & $0(0 \%)$ \\
\hline Tei (\%) & $0(0 \%)$ & $0(0 \%)$ & $0(0 \%)$ \\
\hline Lz (\%) & $0(0 \%)$ & $0(0 \%)$ & $0(0 \%)$ \\
\hline MRSA & $59(64.1 \%)$ & $2(40 \%)$ & $61(62.9 \%)$ \\
\hline
\end{tabular}

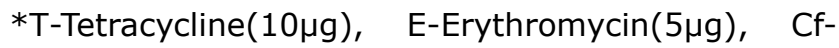
Ciprofloxacin $(5 \mu \mathrm{g}), \quad$ Co-Cotrimoxazole $(1.25 / 23.75 \mu \mathrm{g}), \quad$ Cn-Cefoxitin(30 $\mu \mathrm{g}), \quad$ AC-Amoxyclavulanic acid(50/10 $\mathrm{g})$, Va- Vancomycin $(30 \mu \mathrm{g})$, Tei- Teicoplanin $(30 \mu \mathrm{g})$, Lz-Linezolid $(30 \mu \mathrm{g})$

\section{Discussion}

India belongs to high prevalent countries for CSOM as it is a common childhood disease affecting milestones like early communication and language development and people tend to tolerate the disease and live with its serious complications into adult life [3]. Children in our country are more vulnerable to this disease due to frequent exposure to upper respiratory tract infections. Impaired hearing loss and speech impairment among adults increases the risk of social stigma and decreased avenues of employment. In the current study maximum isolation was seen at a young age i.e. 1120 years $(31 \%)$ followed by $21-30$ years $(29.8 \%)$ which indirectly gives signal regarding acute exposure of otitis media during childhood. A similar age pattern was described in other studies $[7,8]$. Predominant involvement of males $(66.3 \%)$ in the present study corroborates with data reported by other authors $[9,10,11]$. Males are more vulnerable to infection because of increased outdoor activities and decreased attention to personal hygiene.

Attending and managing CSOM cases on the basis of causative agents along with drug susceptibility testing is indispensable for making appropriate clinical decisions. In the current study, organisms were isolated in $66.3 \%$ of the cases with clinically suspected CSOM which is similar to another study from India and other countries $[12,13]$. Pseudomonas spp. (50.7\%) was predominantly isolated followed by $S$. aureus $(27.9 \%)$ which is in comparison with previous studies $[14,15]$.
However, some studies suggested S.aureus [2] or Klebsiella spp [16]. as the most common isolate. This suggests that the microbial spectrum and sensitivity pattern varies with time and place depending on the climatic conditions, geographical area or usage of antimicrobials. Staphylococcus aureus is common in CSOM due to its high carrier rate. Pseudomonas spp. and Proteus spp. gain access to the middle ear via the external auditory canal or defect in the tympanic membrane. Because of the availability of over the counter antibiotics and quacks that practice medicine without any proper qualifications, antimicrobial resistance is now manifested even at the community level hence it is essential to perform antibiotic sensitivity testing among isolates from CSOM.

The present study showed a high level of resistance among Pseudomonas spp. for aminoglycosides and fluoroquinolones but were found sensitive to carbapenems with a resistance rate of $1.2 \%$. Acinetobacter was the most resistant organism isolated among gram-negative bacilli (GNB). All GNR were sensitive to colistin which is the last reserve drug available. ESBL detection was seen in $30.9 \%$ of GNB while MBL was detected in $2.7 \%$ of cases. Among gram-positive isolates, $S$. aureus was highly resistant to first-line antibiotics with MRSA (Methicillin-resistant S. aureus) rate of $64.1 \%$, however, all were sensitive to glycopeptides. These findings are in comparison with previous studies $[14,15,17]$.

Management of CSOM is basically dependent on eradicating infection and closure of the tympanic membrane. For surgical intervention, specialized infrastructure and facilities are required and Policy planners should consider organizing outreach ear clinics so that patients requiring referral for intracranial or extracranial complications can be recommended to the concerned experts.

Also, it is a disease of people with a poor socioeconomic status where they believe in home remedies like the use of earwig, putting mustard oil, ear packing with contaminated cloth, etc. which leads to further complications inactive stage of the disease. Hence counselling and education play a pivotal role in such cases. However, there are certain limitations to the present study. The antimicrobial sensitivity pattern was determined by the disc diffusion method and was not confirmed by the broth dilution method. Also, the follow up of patients was not done after the treatment protocol. 


\section{Conclusion}

The patients of CSOM report to tertiary care centers only on non-response of home remedies and failure of first-line drugs provided by RMPs and quacks or associated complications. Selection of local or systemic antibiotics along with ear toileting should be on the basis of the antibiotic sensitivity pattern of the isolates. There should be a minimum gap between the onset of symptoms and the treatment provided to prevent complications of CSOM and also the complicated cases should be referred to specialized centers for better management.

\section{What does the study add to the existing knowledge?}

This study helps to understand the current scenario of micro-organisms isolated from patients infected with CSOM. This is the first study of its kind from our area and the microbial pattern and their antibiogram were not known. This study adds to the knowledge of first-line antibiotics to be given to the patients as the present study conducted an antimicrobial susceptibility profile in these patients. Also, it helps to frame the antibiotic policy in our hospital for better management and preventing complications in such patients.

\section{Author's contribution}

All the authors, Dr. Shweta R Sharma, Dr. Sudhir Singh, Dr. Amit Mishra, and Dr. Prachi Singh contributed equally in the design, conduct of the study along with the preparation of the manuscript.

\section{Reference}

01. WHO. Chronic suppurative otitis media- Burden of Illness and Management Options. World Heath Organisation. 2004.

Available at [Article:https://apps.who.int/iris/handle /10665/42941][Crossref]

02. Kumar $H$, Seth $S$. Bacterial and fungal study of 100 cases of chronic suppurative otitis media. J Clin Diagn Res. 2011;5;1224-1227.

[Crossref]

03. Bluestone $C D$, Klein JO. Microbiology, InBluestone CD, Klein JO, eds Otitis Media in Infants and Children. 3rd ed, Philadelphia, PAWB Saunders. 2001;79-1014.

[Crossref]
04. Prakash R, Juyal D, Negi V, Pal S, Adekhandi S, Sharma et al. Microbiology of chronic suppurative otitis media in a tertiary care setup in Uttarakhand state, India. North Am J Med Sci. 2013;5(4)282-287.

doi: [Article:https://doi.org/10.4103/19472714.110436][Crossref]

05. Kumar R, Srivastava $P$, Sharma M, Rishi $S$, Nirwan PS, Hemwani $K$ et al. Isolation and antimicrobial sensitivity profile of bacterial agents in chronic suppurative otitis media patients at NIMS hospital, Jaipur. Int J Pharma Biol Sci. 2013;3(4)265-269.

[Crossref]

06. Shrestha B L, Amatya R C M, Shrestha I, Ghosh I. Microbiological profile of chronic suppurative otitis media. Nepalese J ENT, Head and Neck Surg. $2011 ; 2(2) 6-7$.

doi:[Article:https://doi.org/10.3126/njenthns.v2i2. 6793][Crossref]

07. Clinical and Laboratory Standard Institute. Performance Standards for Antimicrobial Susceptibility Testing. Pennsylvania, USAClinical and Laboratory Standard Institute. 2013; Vol 1, No 1, M2 A9.

Available at [Article:https://clsi.org/media/2663/m100ed29_samp le.pdf][Crossref]

08. Mansoor T, Musani MA, Khalid G, Kamal M. Pseudomonas aeruginosa in chronic suppurative otitis media- Sensitivity spectrum against various antibiotics in Karachi. J Ayub Med Coll Abbottabad. 2001;21(2)120-123.

[Crossref]

09. Poorey VK, Lyer A. Study of bacterial flora in csom and its clinical significance. Indian J Otolaryngol Head Neck Surg. 2002;54(2)91-95. doi: [Article:https://doi.org/10.1007/bf02968724] [Crossref]

10. Daly A. Knowledge and attitude about otitis media risk- implication for prevention. J Pediatr. 1997;100(6)931-936.

doi: [Article:https://doi.org/10.1542/peds.100.6.931] [Crossref]

11. Malkappa KS, Kondapaneni S, Supam BR, Chakraverti KT. Study of bacterial isolates and their antibiotic susceptibility pattern in Chronic Supperative Otitis Media. Indian J Otol. 2012;18(3)136-139.

doi: [Article:https://doi.org/10.4103/09717749.103440][Crossref] 
12. Parveen SS and Rao JR. Aerobic bacteriology of Chronic Suppurative Otitis Media (CSOM) in a teaching hospital. J Microbiol Biotechnol Res. 2012;2(4)586-589.

doi:

[Article:https://doi.org/10.9734/IJTDH/2015/13766] [Crossref]

13. Gulati SK. Investigative profile in patients of chronic suppurative otitis media. Indian $\mathrm{J}$ Otol. $1997 ; 3(2) 59-62$.

[Crossref]

14. Gaur RS, Mathew J, Varghese AM, Mathew GA, Chandrasekharan R, Anandan S. Microbiological pattern of ear swabs in chronically discharging ears in a Tertiary Care hospital in India. Indian J Otol. 2013;19(2)51-54.

doi: [Article:https://doi.org/10.4103/09717749.113501][Crossref]
15. Prayaga N, Moorthy S, Lingaiah J, Katari S, Nakirakanti A. Clinical Application of a Microbiological Study on Chronic Suppurative Otitis Media. Int J Otolaryngol Head Neck Surg. 2013;2(6)290-294.

doi:

[Article:http://dx.doi.org/10.4236/ijohns.2013.26060 ][Crossref]

16. Aslam MA, Ahmed Z, Azim R. Microbiology and drug sensitivity patterns of chronic suppurative otitis media. J Coll Physicians Surg Pak. $2004 ; 14(8) 459-461$.

[Crossref]

17. Shyamla R, Reddy SP. The study of bacteriological agents of chronic suppurative otitis media-aerobic culture and evaluation. J Microbiol Biotechnol Res. 2012;2;152-162. [Crossref] 